Cell Research(1995),5,47-58

\title{
Candidate genes of hypertension with defective environmental expression ${ }^{1}$
}

SUN Y u Lin ${ }^{2}$, Johanne TREMBLAY, Dewen KONG, PAVEL HAMET.

Centre de Recherche Hôtel-Dieu de Montréal, Université de Montréal, Montréal, Canada

\section{ABSTRACT}

Previous studies in our laboratory have demonstrated that the thermosensitivity locus cosegregates with blood pressure and that the elevated expression and restriction fragment length polymorphism of HSP70 gene are associated with hypertension. Cell protection against environmental stressors such as heat and chemicals is often accompanied by up-regulated expression of a wide spectrum of heat shock genes $(H S P)$. To further investigate the interrelation between HSP expression and blood pressure regulation, we employed an effective method of cloning 2 potential hypertension-related HSPs. Synthetic oligonucleotides corresponding either to a highly-conserved region of the known HSP family or a repetitive sequence in the proteinencoding gene were used as target primers for polymerase chain reaction (PCR). cDNA prepared from heat-stressed and non-stressed vascular smooth muscle cells (VSMC) of Brown Norway rats (BN.lx) and spontaneously hypertensive rats (SHRp) respectively served as template in the reaction. The PCR products were subsequently analyzed in a single-stranded conformational polymorphism (SSCP) electrophoresing system. Differential gene expression in $\mathrm{BN}$. lx and SHRp was seen on autoradiographs of SSCP gel by comparing the migration patterns of PCR-amplified

1. This article is dedicated to Dr. Zhen YAO commemorating his 80th birthday

2. Requests for reprints should be addressed to Dr. Yu Lin SUN, Laboratory of Molecular Medicine, Centre de Recherche Hôtel-Dieu de Montréal, 3850 St. Urbain St, Montréal, Quebec H2W 1T8, Canada. 
Genes of hypertension with defective environmental expression

DNA fragments. Using this technique, we also found that HSP27 and a new member of the large HSP gene family were differentially expressed in BN. $\mathrm{lx}$ and SHRp VSMC.

Key words: Hypertension, genes, defective expression, polymerase chain reaction, singlestranded conformational polymorphism.

\section{INTRODUCTION}

The search for hypertension-associated genes has become intense. Many genes or gene-containing loci have been identified in the renin-angiotensin system[1-4]. Atrial natriuretic factor [5, 6] and other factors, such as parathyroid hypertensive factor[7], angiotensin-converting enzyme (ACE) [8, 9], BP /sp-1 and BP /sp-2[10, 11], $11 \beta$-hydroxylase /aldosterone synthase[12] and $\mathrm{Na}^{+}-\mathrm{H}^{+}$antiporter[13], have been analyzed as genetic determinants of hypertension. Nevertheless, the search continues, since hypertension is a polygenic trait, and any of these factors cannot yet fully explain the development of this multigene-determined disease.

In the past few years, we have focused on the general stress response of hypertensive patients, animals and cell lines[14-18]. We believe that the abnormal response to various environmental stresses in hypertension is genetically-determined and that genes induced by heat or other stressors, modify the development of hypertension. Heat shock proteins (HSP) include 5 major protein families in mammalian cells, denoted as HSP110, HSP90, HSP70, HSP27 and HSP8.5 according to their approximate molecular weight[19]. The genes encoding HSP are highly conserved evolutionally and play important roles in normal cell function[19-24]. HSP27, HSPT0 and HSP104 have been found to be involved in the regulation of thermotolerance[25-28]. We have reported previously that abnormal HSP70 gene expression is evident in hypertensive subjects and animals after exposure to heat and other stressful stimuli[15, $16,29]$ and the restriction fragment length polymorphism (RFLP) of the HSP70 locus segregates with an increment of blood pressure in 30 recombinant inbred strains (RIS) of rats[18].

To further determine and isolate the genes associated with hypertension development, especially genes induced transcriptionally by heat or other environmental stresses, we have used an effective approach that combines polymerase chain reaction (PCR) and single-stranded conformational polymorphism (SSCP)[30, 31]. Two genes were found with this approach. They are HSP27 and a new member of the large HSP gene family. Both display significant differential expression under heat stress in normotensive and hypertensive rats. 
Sun YL et al.

\section{METHODS}

\section{Cell culture, preparation of DNA, RNA and cDNA and construction of cDNA library}

Vascular smooth muscle cells (VSMC) isolated from Brown Norway rats (BN.lx) and spontaneously hypertensive rats(SHRp) were maintained in culture as described previously[32]. BN.lx and SHRp livers were provided by the Institute of Physiology, Czech Academy of Science, and the Biology Institute at Charles University in Prague. Genomic DNA was prepared as described elsewhere[18]. VSMC from BN. lx and SHRp were used for total RNA preparation, and RNA was extracted as outlined eaxlier[33]. To heat shock the cells, cell-containing flasks were incubated in a water bath at $45.5{ }^{\circ} \mathrm{C}$ for $20 \mathrm{~min}$. The cells were allowed to recover at $37{ }^{\circ} \mathrm{C}$ for $2 \mathrm{~h}$ before RNA extraction. For cDNA preparation, total RNA or mRNA was subjected to reverse transcription (RT) as described by Sambrook et a1[34]. A cDNA library was constructed as detailed in Instruction Manual 8090 of BRL Laboratories, the system of choice for cDNA synthesis, pUC19 plasmid served as the ligation vector and the DH5a strain of E. Coli was used for transformation.

\section{Oligonucleotides, PCR and SSCP gel system}

Oligonucleotides were designed according to the rat HSP70 sequence: Oligo 2, one of these, is an antisense sequence that is 10 bases downstream from the start site of translation. Its sequence (5'CAGGTCGATGCC.GATCGCAG-3' ) is common to different HSP70 members[35-37, X74271 and Z27118 in GenEMBL]. Homologue of the HSP27 motif (5'-CCGGAATTCTTGATGACGGCT-3') is denoted as oligo R2C, from +583 to +602 on the sequence cloned by Gilmont and Welsh [M866389 in GenEMBL]. A series of HSP27-related oligonueleotides is shown in Fig 3A. (these sequences axe available upon request). Oligonucleotides synthesis and purification followed the procedures outlined in Gene Assembler Plus Synthetizer (LKB pharmacia Canada Inc., Baie d'Urfé, Quebéc). Each PCR mixture contained $100 \mathrm{ng}$ genomic DNA or $1-5 \mathrm{ng}$ cDNA as template and $40 \mathrm{pmol}$ of each oligonucleotide in $50 \mu 1$ of total reaction volume. PCR was conducted for 30 cycles, each consisting of $1 \mathrm{~min}$ of denaturation at $94{ }^{\circ} \mathrm{C}, 2 \mathrm{~min}$ of annealing at the temperatures described in the figure legends, and $3 \mathrm{~min}$ of polymerization at $72{ }^{\circ} \mathrm{C}$, and followed by $7 \mathrm{~min}$ of elongation after last cycle. The PCR products were tagged by $\left[{ }^{-32} \mathrm{P}\right]$ ATP-labelled oligonucleotide or by the addition of $\left[a{ }^{32} \mathrm{P}\right]$ dATP to a dNTP mixture. The SSCP gel system was set up as described by Orita et al.[31]. Briefly, 1-3 $\mu 1$ of lablled PCR product were mixed with formamide-loadin buffer, boiled for 5 rain, snap-cooled and then loaded immediately onto $5 \%$ polyacrylamide- $10 \%$ glycerol gel. DNA was electrophoresed at a constant $30 \mathrm{~W}$ at room tremperature. After electrophoresis, the gel was transferred and dried on a Whatman filter. It was then exposed, scanned and analyzed with a PhosphorImager (Molecular Dynamics, San Diego, CA).

\section{DNA elution, cloning and sequencing}

To elute DNA fragments from the SSCP gel, after localization of a desired DNA band on undried gel by autoradiography, the gel was sliced and suspended overnight in TE buffer at $4{ }^{\circ} \mathrm{C}$. The eluted DNA was reamplified with the same oligonucleotides and then subcloned into the EcoRI site of pUC19 vector. Sequencing was done with the pUC sequencing kit (1013106, Boehringer Manheim, Laval, Quebec). Northern hybridization was performed as described elsewhere[33].

\section{RESULT}

\section{Differential expression of genes induced by heat stress}

Using oligonucleotides designed according to the HSP70 sequence as primers and cDNA prepared respectively from BN.1x and SHRp VSMC mRNA as templates in PCR, no significant difference was found between BN.lx and SHRp after SSCP 
Genes of hypertension with defective environmental expression

analysis (data not shown). We also used one HSP70-derived oligonucleotide together with a non-specific oligonucleotide such as the rat repetitive sequence, the single nucleotide-repeated sequence or another often appearing sequence in rat cDNA. Again, no significant difference was found (data not shown), except that oligo 2 and oligo $\mathrm{d}(\mathrm{T})$ (17 mer) produced a clearly different SSCP pattern in the 2 strains (Fig 1A). Under non-heat stress conditions (indicated by CTL in Fig 1A), bands S3 to S5 in lane SHR were stronger than the corresponding bands in lane BN.lx. After heat shock, bands S3 and S4 decreased (compare CTL with HS in lane SHRp of Fig 1A), while bands B1 to B6 in lanes BN.lx and S1 and S2 in lanes SHRp were enhanced (compare HS with CTL in Fig 1A), indicating heat-inducible expression of the c.orresponding genes. The SSCP pattern revealed by oligo 2 and oligo $\mathrm{d}(\mathrm{T})$ resulted from the amplification of several genes whose expressions were affected by heat stress. Since oligo 2 is an antisense of the coding region, its combination with oligo $d(T)$ would not amplify genes according to the sequnce for oligo design and poly (A) tail of these cDNA. However, oligo $d(T)$ targeted on an upstream sequence from oligo 2 or oligo 2 targeted on a partial homologue sequence in the sense direction needs to be determined. The identities and significance of the bands appearing in Fig 1A remain to be further analyzed. This highly-polymorphic pattern can be useful for genetic studies, such as linkage and association investigations.

Oligo R2C (20 mer) was designed according to the coding sequence of HSP27 gene (see Methods), but the eighth nucleotide (G) was replaced by $\mathrm{T}$ to generate an EcoRI restriction site, and other 4 nucleotides (position $9(\mathrm{G}), 14(\mathrm{C}), 15(\mathrm{~T})$ and 17(C)) were replaced by C, G, A and G respectively, to generate a homologue with a sequence in the 3'-untranslated region (3'-UTR) (site 694-713 in the Gilmont and Welsh sequence). Oligo R2C also possessed high homology to dnaK and dnaJ (site 852-871) in Brucella Ovis HSP70 and HSP40 respectively[38], and to yeast drug resistance protein gene (site 690-708) (L24961, in GenEMBL).

Using single oligo R2C and cDNA templates for PCR-SSCP analysis effectively revealed a difference between BN.x and SHRp VSMC. Four prominent heat-induced bands were clearly visible on the SSCP gel (RB1 to RB4 in lane BN.lx of HS, Fig 1B). The RS1 band appeared in non-heat-stressed SHRp VSMC but not in BN.lx VSMC (lanes SHRp of CTL and HS, Fig 1B). Since the polymorphic bands RB1 to RB4 were observed only in heat-stressed BN.lx VSMC, oligo R2C appeared to be a specific primer for targeting HSP genes of BN.lx.

\section{Identification of HSP27 gene and its differential expression in BN.lx and SHRp VSMC}

To further identify the DNA fragment amplified from $\mathrm{HSP} 27$ cDNA by oligo R2C, RB4 DNA was eluted and cloned into EcoRI site of pUC19 vector because it corresponds to the size derived from HSP27 cDNA. The cloned RB4 DNA was then used as a probe for Norhtern hybridization analysis. Total RNA was extracted from 
BN.lx and SHRp VSMC after exposure to $45.5^{\circ} \mathrm{C}$ for $20 \mathrm{~min}$ and recovery at $37^{\circ} \mathrm{C}$ for 2 and $4 \mathrm{~h}$ respectively. Indeed, Northern hybridization to these RNA revealed an HSP27 mRNA band strongly induced by heat stress (Fig 2). This band was equally induced in both BN.lx and SHRp VSMC in the 2-h stage under which contition oligo R2C failed to produce RB4 (see lane SHRp of HS in Fig 1B), indicating the presence of an alteration in the sequence targetted by oligo R2C in the cDNA of SHRp VSMC.

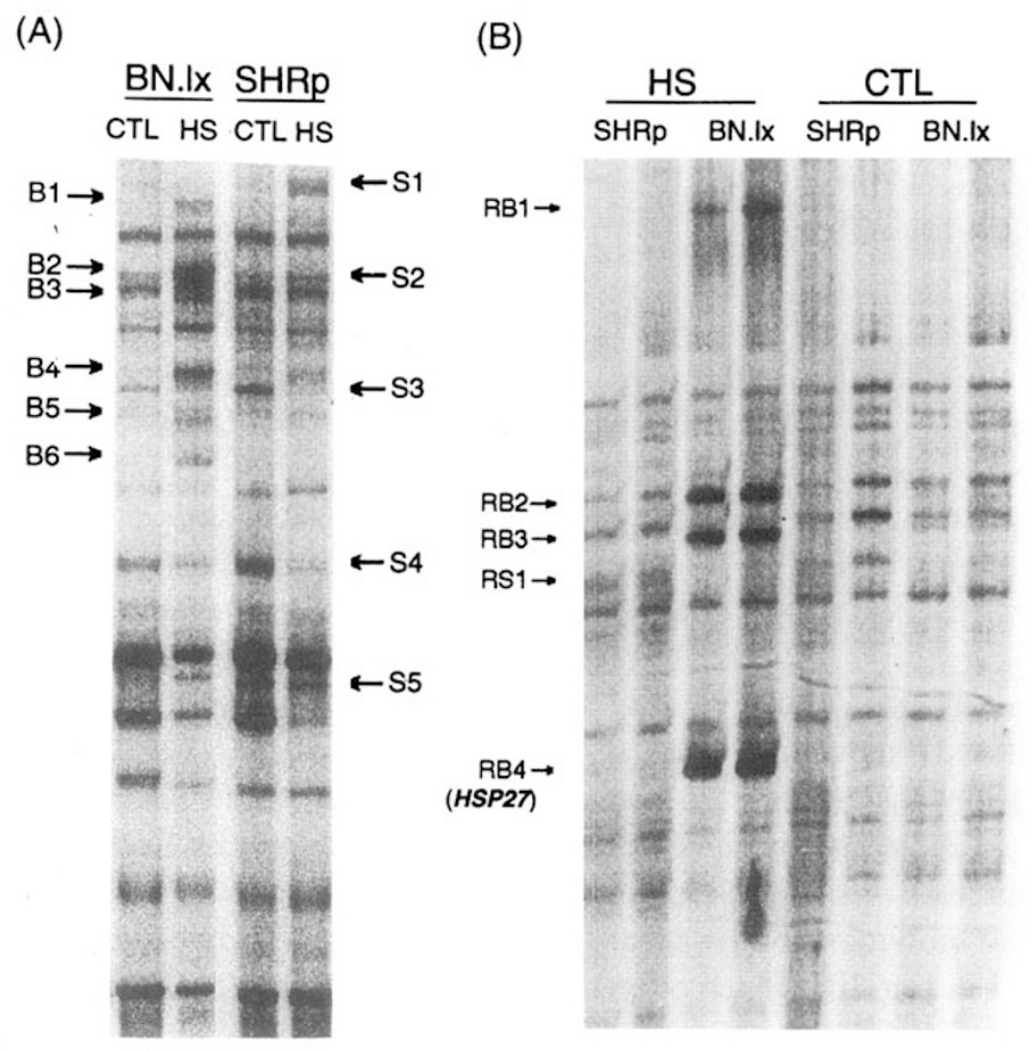

Fig 1. Identification of PCR products by SSCP. The templates were cDNA prepared reverse-transcriptionally from total RNA of BN.1x and SHRp VSMC which were not heated (lanes CTL in panels A and B) or heated for 20 min at 45.5 ${ }^{\circ} \mathrm{C}$ and then allowed to recover for $2 \mathrm{~h}$ at $37^{\circ} \mathrm{C}$ (lanes HS in panels $\mathrm{A}$ and $\mathrm{B}$ ). The primers were oligo 2 and oligo $\mathrm{d}(\mathrm{T})$ in panel $\mathrm{A}$ and oligo $\mathrm{R} 2 \mathrm{C}$ in panel $\mathrm{B}$. Annealing temperature in PCR was $65{ }^{\circ} \mathrm{C}$ in panel $\mathrm{A}$ and $55^{\circ} \mathrm{C}$ in panel $\mathrm{B}$. For details on PCR conditions and the SSCP gel system, see Methods.

Northern hybridization also indicated an overall defective expression of HSP27 in SHRp VSMC. Maximum induction in BN.lx VSMC occurred $4 \mathrm{~h}$ after heat stress. At this stage, it was 10-fold higher than in SHR VSMC (compare last 2 lanes in Fig 2). 


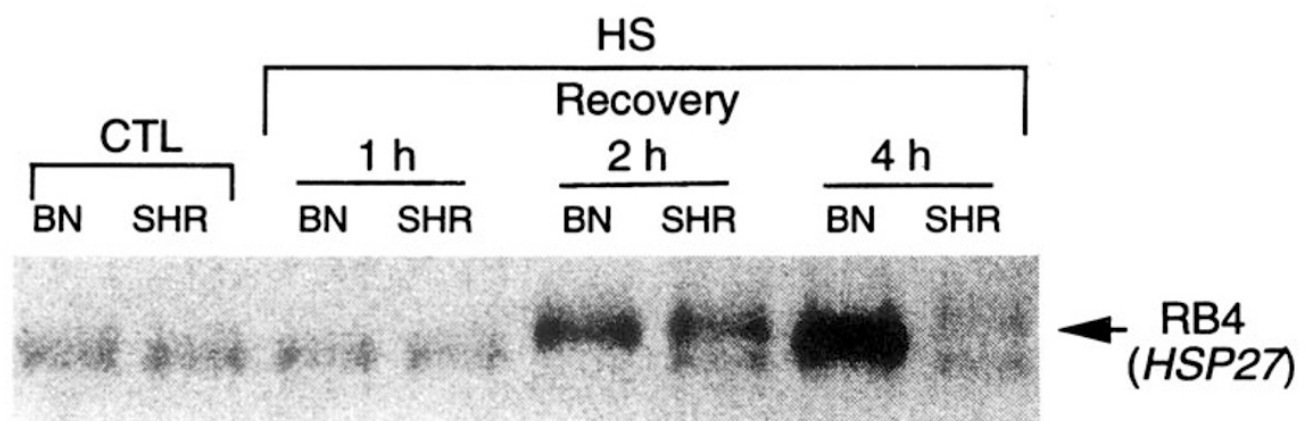

Fig 2. Differentail accumulation of RB4 (HSP27) transcipts in BN.1x and SHRp VSMC after heat stress. BN.1x and SHRp VSMC were heat stressed (HS) for $20 \mathrm{~min}$ at $45.5{ }^{\circ} \mathrm{C}$ and then allowed to recover for 1,2 and $4 \mathrm{~h}$ respectively. CTL indicates non-heat-stressed cells. For details of total RNA extraction from VSMC and Northern hybridization, see Methods.

RB4 DNA was subsequently and its identity was further confirmed. The total 131 base pairs of RB4 had $100 \%$ identity to the region from site 583 to 713 of HSP27 cDNA cloned from Fisher rats by Gilmont and Welsh (see Methods), and the genomic gene cloned from Sprague Dawley rats by Vashima et al.[39].

To determine whether the region targetted by oligo $\mathrm{R} 2 \mathrm{C}$ on this gene was polymorphic between BN.lx and SHRp, we synthesized 5 oligonucleotides encompassing the entire RB4 region in PCR (Fig 3A). Since this region did not contain an intervening sequence, genomic DNA was used in PCR instead of cDNA. The results of SSCP analysis are shown in Fig 3B (a continuum of the gel in Fig 4A). Combination of oligo 27-3 with either oligo 27-1, oligo 27-2 or oligo 27-4 did not produce polymorphic bands (as indicated by the corresponding oligonucleotides in Fig 3B). However, oligo 27-5 instead of oligo 27-3, combinated with the above oligonucleotides, appeared a clear polymorphic pattern (indicated by arrows for combinations of oligo $2+5$ and $4+5$ in Fig $3 \mathrm{~B}$ ). Since oligo 27-5 was right next to the oligo R2C targetted sequence and oligo 27-3 was right in front, the polymorphism should be created only by the oligo R2C targetted sequence, that is, the sequence covered by oligo R2C was different between BN.1X and SHRp HSP27 genes.

\section{Identification of a new member of the large HSP gene family}

In addtition to the bands shown in Fig 3B, using oligo 27-1, oligo 27-2 or oligo 27-4 with oligo 27-3 in PCR-SSCP also identified a group of slow migrating bands (Fig 4A), denoted as W1, which indicated the presence of a gene sharing some common sequence with HSP27 in the region matched by the 4 oligonucleotides. We used cDNA as template and oligo 27-2 and oligo 27-3 as primers in PCR to amplify W1 DNA, which was then eluted and cloned. Two clones (W1-1 and W1-7) among 7 clones selected positively with the W1 probe were further investigated. After sequencing analysis, W1-7 DNA was identified as a partial sequence of HSP27 which 
covered the RB4 sequence (Fig 1B) and $250 \mathrm{bp}$ further down to the 3 ' end of the gene. Wl-1 DNA was identified as a new gene not listed in GenEMBL. Using W1-1 as a probe, we obtained a clone denoted as HSPW1 from the BN.lx VSMC cDNA

Fig 3. Identification by SSCP of RB4 DNA fragment of the 3' region of HSP27 gene. Panel A: Localization of oligonucleotide primers on HSP27. Panel B: SSCP pattern in the 3' -UTR region of HSP27 in BN.lx (B) and SHRp (S). Templates: liver genomic DNA; primers: oligonucleotides are indicated in the top lane and panel A for localization. Annealing temperature was $65{ }^{\circ} \mathrm{C}$. Arrows point to polymorphic bands in BN.lx (B) and SHRp (S).

(A)

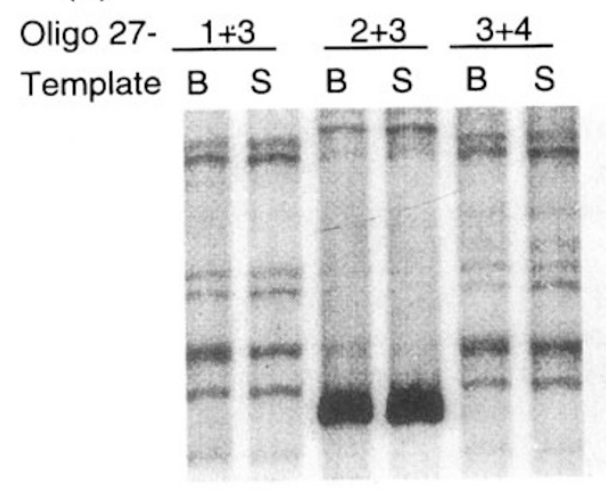

(A)

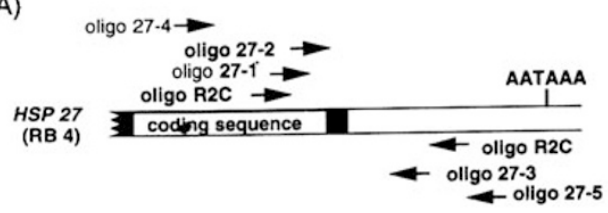

(B)

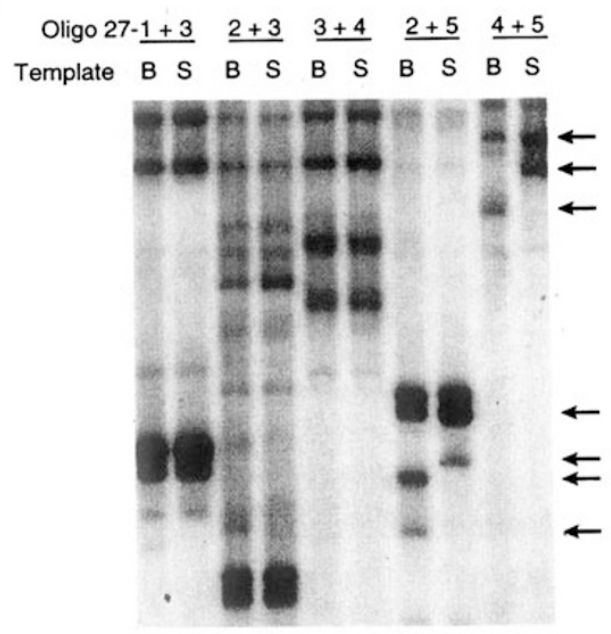

(B)

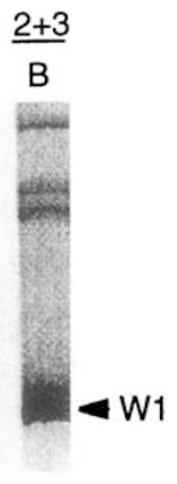

Fig 4. Identification of $\mathrm{W} 1$ DNA by SSCP. Panel A indicates the top part of the partial gel in panel $\mathrm{B}$ of Fig 3 . B and $\mathrm{S}$ show genomic DNA templates obtained from BN. lx and SHRp livers respectively. Panel B parallels lane B of oligo 27-2+3 in pane1 A but uses cDNA template instead. W1 DNA fragement(s) was obtained by both templates in PCR. 
Genes of hypertension with defective environmental expression

library. HSPW1 hybridized a $3 \mathrm{~Kb}$ mRNA band on Northern blot (Fig 5). HSPW1 mRNA accumulated significantly in the early stage of recovery and then decreased dramatically with time in SHRp VSMC (lanes HS-SHR at 2 and $4 \mathrm{~h}$ in Fig 5). However, mRNA accumulation in BN.1x VSMC increased continuously although it was less during the early stage than in SHRp VSMC.

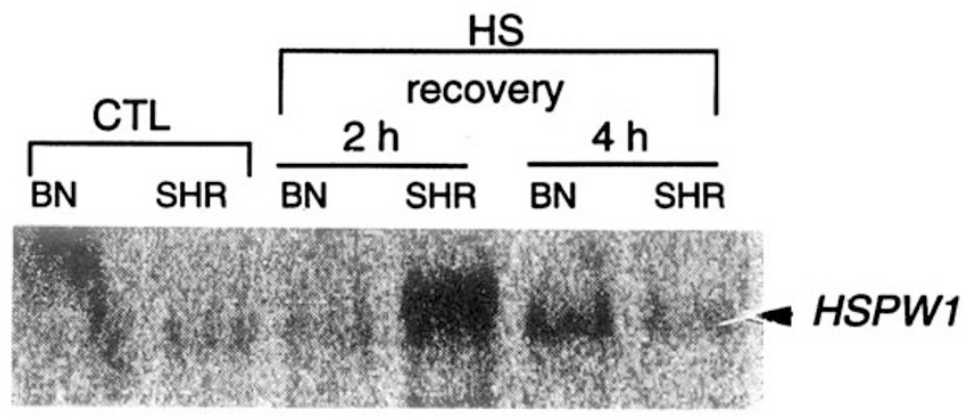

Fig 5. Identification of HSPW1 mRNA by Northern hybridization. Total RNAs, were prepared from BN.lx (BN) and SHRp (SHR) VSMC respectively. CTL indicates non-heat-stressed control samples, and HS heat-stressed RNA samples. Heat stress was applied at $45.5^{\circ} \mathrm{C}$ for $20 \mathrm{~min}$. Recovery time was $2 \mathrm{~h}$ and $4 \mathrm{~h}$ after heat stress. The probe used was [a $\left.{ }^{32} \mathrm{P}\right]$-labelled cloned HSPW1 DNA. For other conditions see Methods.

HSPW1: 1 tgagatcatcaAggtccacttTactgagatgagcacactgaattTagaA 50

ID: $1 \ldots \ldots \ldots \ldots \ldots \ldots \ldots \ldots \ldots . \ldots \ldots$ GGGTGGGAT 11

HSPW1: 51 GTCTCATTAAAGTAGAGCGCTTGCCTAGGAAGCGCAAGGCCCTGGGTTCG 100

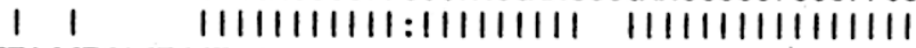

ID: 12 TTAGCTCAGTGGTAGAGCGCTTRCCTAGGAAGRYCAAGGCCCTGGGTTCG 61

HSPW1: 101 GTCCCCAGCTCTGAAAAAAAGAACCAAAAAAAAAAAAA 137 IIIIIIIIIII IIIIIII: II

ID: 62 GTCCCCAGCTCCGAAAAAARAAAA..........85

Fig 6. Alignment of the 3 '-UTR of HSPW1 cDNA with the consensus sequence of rat ID element. The HSPW1 DNA sequence was the last 137 nucleotides at the 3'-end of cloned cDNA. The ID element refers to the sequence reported by Glaichenhaus and Cuzin[40].

The HSPW1 cDNA obtained in this experiment was $1.1 \mathrm{~K}$ base pairs in length and apparently not of full length. The 3'-UTR of this gene consists of a rat identifier element (ID)[40] (Fig 6). It has 75\% identity to the consensus sequence. Further cloning of HSPW1 gene is in progress. 


\section{DISCUSSION}

The quantity of cDNA reverse-transcribed by oligo $d(T)$ from total RNA generally represents the mRNA level of cells. This level is proportionally amplified by PCR and determined by SSCP. Therefore, the results obtained with the PCR-SSCP gel system are generally comparable to either the activity of gene expression or the stability of mRNA transcripts. However, this is only the case when primers used in PCR are perfectly matched with the target sequence of the template. When annealing efficiency of the primers differs from the source of the DNA template, the result will not reflect the level of gene expression, as indicated by oligo $\mathrm{R} 2 \mathrm{C}$ in this report. Thus, the different expression of the gene and kinetics of RNA accumulation should be evaluated by Northern hybridization or by using more effective oligonucleotides. Nevertheless, both differentially expressed genes and differential oligo-matching sequences are the aim of such searches. The latter may be implicated in the possible founding of a mutated disease-causing gene.

To increase the power of this technique, ologonucleotides with a consensus sequence to target genes may be used in order to look at a gene family rather than a single gene. This is advantageous in linkage or association studies, to survey multiple loci. To augment these probabilities in PCR, a condition that targets as many DNA as possible in an permissive background may also be selected: decreasing the annealing temperature in PCR often increases chances. A mixture of an oligonucleotide that possesses one or more nucleotide replacements with oligonucleotides containing a short repetitive sequence or a short string of one kind of nucleotide can also be used in PCR.

Oligo R2C used in this study was selected according to multiple genes revealed from DNA query in GenEMBL. Therefore, it did not perfectly match the HSP27 sequence. Howevever, under the conditions reported here, it could anneal both cDNA strands in 2 neighbouring sites to produce a $151 \mathrm{bp}$ DNA fragment in PCR.

We used heat stress as an environmental stimulus to search for genes which respond abnormally in hypertensive cells. We believe that this procedure can be commonly applied with various stressful factors in different diseases as long as they can induce the specific expression of target genes.

Here, we report on $2 \mathrm{HSP}$ genes which expressed differential patterns of mRNA accumulation in BN.1x and SHRp. Oligo 27-2 and oligo 27-5 (Fig 3B) further indicate a distinct polymorphism pattern of HSP27 in the 2 model strains. Recently, HSP27 has received much attention due to its potential function in the regulation of cell growth[20, 41-44] in addition to its role in thermo- and drug-resistance[45, 46] as well as in cell defence as a molecular chaprone[23]. HSP27 may elicit phosphorylation related to the signalling function when normal growing cells are exposed to various environmental stimuli[46-51]. We have reported earlier that SHR VSMC in culture display a shorter transition from G1 to S[15]. The relationship between the abnormal growth of hypertensive VSMC and the abnormal expression of HSP27 gene may be 
implicated in a common step in the process of signal transduction.

$H S P W 1$ gene is a new member of the large HSP gene family. It is the first rat heat shock gene found to possess a rat ID element at the 3'-UTR. Interestingly, this element was reported to be a determinant of growth factor-induced transition of normal rat fibroblasts from a quiescent to a proliferative state[40], indicating that HSPW1 may be regulated by similar growth factors. Since this gene is differentially' expressed by heat stress in BN.lx and SHRp VSMC, we are encouraged to further investigate its identity, biological function and potential role in hypertension.

\section{ACKNOWLEDGEMENTS}

The authors acknowledge support from MRC Canada (10803) and the Dairy Bureau of Canada. The technical expertise of Carole long, Gilles Corbeil and Régis Tremblay, the secretarial skills of Josée Bédard-Baker and the editorial assistance of Ovid Da Silva are appreciated.

\section{REFERENCES}

[1] Peach MJ. Renin-angiotensin system: biochemistry and mechanisms of action. Physiol Rev 1977; 57:313-70.

[2] Campbell DJ. Circulating and tissue angiotensin systems. J Clin Invest 1987; 79:1-6.

[3] Mullins J J, Peters J, Ganten D. Fulminant hypertension in transgenic rats haxbouring the mouse Ren-2 gene. Nature 1990; 344:541-4.

[4] Caulfield M, Lavender P, Farrall M, et al. Linkage of the angiotensinogen gene to essential hypertension. N Engl J Med 1994; 330:1629-33.

[5] Deng Y, Rapp JP. Cosegregation of blood pressure with angiotensin converting enzyme and atrial natriuretic peptide receptor genes using Dahl salt-sensitive rats. Nature Gen 1992; 1:26772 .

[6] Tremblay J, Huot C, Willenbrock RC, et al. Increased cyclic guanosine monophosphate production and over expression of atrial natriuretic peptide A-receptor mRNA in spontaneously hypertensive rats. J Clin Invest 1993; 92:2499-508.

[7] Benishin CG, Lewanczuk RZ, Pang PKT. Purification of parathyroid hypertensive factor from palsma of spontaneously hypertensive rats. Proc Natl Acad Sci USA 1991; 88:6372-6.

[8] Harrap SB, Davidson HR, Connor JM, et al. The angiotensin I converting enzyme gene and predisposition to high blood pressure. Hypertension 1993; 21:455-60.

[9] Jeunemaitre X, Lifton RR, Hunt SC, Williams RR, Lalouel JM. Absence of linkage between the angiotensin converting enzyme locus and human essentail hypertension. Nature Gen 1992; 1:72-5.

[10] Hilbert P, Lindpaintner K, Beckmann JS, et ah Chromosomal mapping of two genetic loci associated with blood-pressure regulation in hereditary hypertensive rats. Nature 1991; 353:5219.

[11] Jacob HJ, Lindpainter K, Lincoln SE, et al. Genetic mapping of a gene causing hypertension in the stroke-prone spontaneously hypertensive rat. Cell 1991; 67:213-24.

[12] Lifton RP, Dluhy RG, Powers M, et al. A chimaeric $11 \beta$-hydroxylase/aldosterone synthase gene causes glucocorticoid-remediable aldosteronism and human hypertension. Nature 1992; 355:262-5.

[13] Lifton RP, Hunt SC, Willams RR, Pouyssegur J, Lalouel JM. Exclusion of the $\mathrm{Na}^{+}-\mathrm{H}^{+}$antiporter as a candidate gene in human essential hypertension. Hypertension 1991; 17:8-14. 
[14] Malo D, Schlager G, Tremblay J, Hamet P. Thermosensitivity, a possible new locus involved in genetic hypertension. Hypertension 1989; 14:121-8.

[15] Hamet P, Malo D, Tremblay J. Increased transcription of a major stress gene in spontaneously hypertensive mice. Hypertension 1990; 15:904-8.

[16] Tremblay J, Hadrava V, Kruppa U, Hamet P. Enhanced growth-dependent expression of TGF $\beta 1$ and hsp70 genes in aortic smooth muscle cells from spontaneously hypertensive rats. Can J physiol Pharmacol 1992; 70:565-72.

[17] Pravenec M, Sun YL, Kunes J, et al. Environmental susceptibility in hypertension: potential role of HSP70 and TNF a genes. J Vasc Med Biol 1991; 3:297-302.

[18] Hamet P, Kong D, Pravenec M, et al. Restriction fragment length polymorphism of hsp70 gene, localized in the RT1 complex, is associated with hypertension in spontaneously hypertensive rats. Hypertension 1992; 19:611-4.

[19] Lindquist S, Craig EA. The heat-shock protein. Annu Rev Genet 1988; 22:631-77.

[20] Ang D, Liberek K, Skowyra D, Zylicz M, Georgopoulos C. Biological role and regulation of the universally conserved heat shock proteins. J Biol Chem 1991; 36:24233-6.

[21] Pechan PM. Heat shock proteins and cell proliferation. FEBS Lett 1991; 280:1-4.

[22] Young RA. Stress proteins and immunology. Annu Rev Immunol 1990; 8:401-20.

[23] Georgopoulos C. Role of the major heat shock proteins as molecular chaperones. Annu Rev Cell Biol 1993; 9:601-34.

[24] Parsell DA, Lindquist S. The function of heat-shock proteins in stress tolerance: degradation and reactivation of damaged proteins. Annu Rev Genet 1993; 27:437-96.

[25] Lee Y J, Hou ZZ, Curetty L, Corry PM. Expression, synthesis, and phosphorylation of the HSP28 family during development and decay thermotolerance in CHO plateau-phase cells. J Cell Physiol 1992; 150:441-6.

[26] Landry J, Chretien P, Lambert H, Hickey E, Weber LA. Heat shock resistance conferred by expression of the human HSP27 gene in rodent cells. J Cell Biol 1989; 109:7-15.

[27] Li GC, Li L, Liu YK, Mak JY, Chen LL, Lee WMF. Thermal response of rat fibroblasts stably transfected with the human $70-\mathrm{kDa}$ heat shock protein-encoding gene. Proc Natl Acad Sci USA 1991; 88:1681-5.

[28] Sanchez Y, Taulien J, Borkovich KA, Lindquist S. Hspl04 is required for tolerance to many forms of stress. EMBO J 1992; 11:2357-64.

[29] Kunes J, poirier M, Tremblay J, Hamet P. Expression of hsp70 gene in lymphocytes from normotensive and hypertensive humans. Acta physiol Seand 1992; 146:307-11.

[30] Wu DY, Ugozzoli L, Pal BK, Qian J, Wallace B. The effect of temperature and olionucleotide primer length on the specificity and effeciency of amplification by the polymerase chain reaction. DNA Cell Biol 1991; 10:233-8.

[31] Orita M, Suzuki Y, Sekiya T, Hayashi K. Rapid and sensitive detection of point mutations and DNA polymorphisms using the polymerase chain reaction. Genomics 1989; 5:874-9.

[32] Hadrava V, Tremblay J, Hamet P. Abnormalities in growth characteristics of aortic amooth muscle cells in spontaneously hypertensive rats. Hypertension 1989; 13:589-97.

[33] Sun YL, Pao CI, Sen S, Kuo T. High-resolution mapping of DNAase I hypersensitive site in the chichen $\beta$-tubulin gene transfected into monkey cells. J Biol Chem 1 987; 262:7764-9.

[34] Sambrook J, Fritsch EF, Maniatis T. Molecular cloning: A Laboratory Manual. Cold Spring Harbor: Cold Spring Harbor Laboratory 1989:Ed.2 pp6.53.

[35] Drabent B, Genthe A, Benecke BJ. In vitro transcription of a human hsp70 heat shock gene by extracts prepared from heat-shocked and non-heat-shocked human cells. Nucleic Acids Res $1986 ; 14: 8933-48$.

[36] Long OFM, Wang S, Narasimhan P, et al. cDNA cloning and expression of stress-inducible rat hsp70 in normal and injured rat brain. J Neurosci Res 1993; 36:325-35.

[37] Wisniewski J, Kordula T, Krawczyk Z. Isolation and nucleotide sequence analysis of the rat testis-specific major heat-shock protein (HSP70)-related gene. Biochim Biophys Acta 1990; 


\section{Genes of hypertension with defective environmental expression}

1048:93-9.

[38] Cellier MF, Teyssier J, Nicolas M, Liautard JP, Marti J, Sri Widada J. Cloning and characterization of the Brucella ovis heat shock protein DnaK functionally expression in Escherichia coli. J Bacteriol 1992; 174:8036-42.

[39] Voshima K, Handelman B, Cooper LF. Isolateion and characterization of a rat HSP27 gene. Biochem Biophys Res Commun 1993; 197:1388-95.

[40] Glalchenhaus N, Cuzin F. A role for ID repetitive sequences in growth- and transformationdependent regulation of gené expression in rat fibroblast. Cell 1987; 50:1081-9.

[41] Luo Y, Amin J, Voellmy R. Ecdysterone receptor is a sequence-specific transcription factor involved in the developmental regulation of heat shock genes. Mol Cell Biol 1991; 11:3660-3675.

[42] Michishita M, Satoh M, Yamaguchi M, Hirayoshi K, Okuma M, Nagata K. Phosphorylation of the stress protein HSP27 is an early event in murine myelomonocytic leukemic cell differentiation induced by leukemia inhibitory factor/D-factor. Biochem Biophys Res Commun 1991; 176:97984 .

[43] Marui N, Nishino H, Sakai T, Aoike A, Kawai K, Fukushima M. Delta 12-Prostaglandin J2 mimics heat shock in inducing cell cycle arrest at G1 phase. Biochem Biophys Res Commun 1991; 179:1662-9.

[44] Spector NL, Samson W, Ryan C, et al. Growth arrest of human B lymphocytes is accompanied by induction of the low molecular weight mammalian heat shock protein (Hsp28). J Immunol 1992; 148:1668-73.

[45] Huot J, Roy G, Lambert H, Chretien P, Landry J. Increased survival after treatments with anticancer agents of chinese hamster cells expressing the human $\mathrm{Mr}$ 27,000 heat shock protein. Cancer Res 1991; 51:5245-52.

[46] Landry J, Lambert H, Zhou M, et al. Human HSP27 is phosphorylated at serines 78 and 82 by heat shock and mitogen-activated kinases that recognize the same amino acid motif as S6 kinase II. J Biol Chem 1992; 267:794-803.

[47] Zhou M, Lambert H, Landry J. Transient activation of a distinct serine protein kinase is responsible for $27-\mathrm{kDa}$ heat shock protein phosphorylation in mitogen-stimulated and heat-shocked cells. J Biol Chem 1993; 268:35-43.

[48] Mendelsohn ME, Zhu Y, O'Neill S. The 29-kDA proteins phosphorylated in thrombin-activated human platelets are forms of the estrogen receptor-related 27-kDA heat shock protein. Proc Natl Acad Sci USA 1991; 88:11212-6.

[49] Bitar KN, Kaminski MS, Hailat N, Cease KB, Strahler JR. HSP27 is a mediator of sustained smooth muscle contraction in response to bombesin. Biochem Biophys Res Commun 1991; 181:1192-200.

[50] Arrigo AP. Tumor necrosis factor induces the rapid phosphorylation of the mammalian heat shock protein hsp28. Mol Cell Biol 1990; 10:1276-80.

[51] Welch WJ. Phorbol ester, calcium ionophore, or serum added to quiescent rat embryo fibroblast cells all result in the elevated phosphorylation of two 28,000-Dalton mammalian stress proteins. J Biol Chem 1985;260:3058:62. 